\title{
The association between PM2.5 exposure and suicidal ideation: a prefectural panel study
}

\author{
Yunsong Chen ${ }^{1 *}$, Guangye He ${ }^{2^{*}}$ (D), Buwei Chen ${ }^{3^{*}}$, Senhu Wang ${ }^{4}$, Guodong Ju² and Ting $\mathrm{Ge}^{2}$
}

\begin{abstract}
Background: Suicidal ideation is subject to serious underestimation among existing public health studies. While numerous factors have been recognized in affecting suicidal thoughts and behaviors (STB), the associated environmental risks have been poorly understood. Foremost among the various environment risks were air pollution, in particular, the PM2.5. The present study attempted to examine the relationship between $\mathrm{PM}_{2.5}$ level and local weekly index of suicidal ideation (ISI).

Methods: Using Internet search query volumes in Baidu (2017), the largest internet search engine in China, we constructed a prefectural panel data (278 prefectures, 52 weeks) and employed dynamic panel GMM system estimation to analyze the relationship between weekly concentration of PM2.5 (Mean $=87 \mu \mathrm{g} \cdot \mathrm{m}^{-3}$ ) and the index of suicidal ideation (Mean $=49.9$ ).

Results: The results indicate that in the spring and winter, a $10 \mu \mathrm{g} \cdot \mathrm{m}^{-3}$ increase in the prior week's $\mathrm{PM}_{2.5}$ in a Chinese city is significantly associated with 0.020 increase in ISI in spring and a 0.007 increase in ISI in winter, after taking account other co-pollutants and meteorological conditions.

Conclusion: We innovatively proposed the measure of suicidal ideation and provided suggestive evidence of a positive association between suicidal ideation and $\mathrm{PM}_{2.5}$ level.
\end{abstract}

Keywords: $\mathrm{PM}_{2.5}$, Suicidal ideation, Internet search

\section{Background}

Suicide has long been one of the most prominent and published public health problems, accounting for 800, 000 deaths worldwide each year, according to the World Health Organization [1]. Far more common, however, are suicidal ideation and suicide attempts [1, 2]. In United States, each year, there are an estimated 25

\footnotetext{
*Correspondence: yunsong.chen@nju.edu.cn; hgy.gloria@nju.edu.cn; chenbuwei@jsph.org.cn

${ }^{1} J o h n s$ Hopkins University-Nanjing University Center for Chinese and American Studies, Gulou District, Nanjing 210093, China

${ }^{2}$ School of Social and Behavioral Sciences, Nanjing University, 163 Xianlin Road, Qixia District, Nanjing 210023, China

${ }^{3}$ The First Affiliated Hospital with Nanjing Medical University, Nanjing 210029, China

Full list of author information is available at the end of the article
}

million suicide attempts [3] and another 140 million individuals who have suicidal thoughts but haven't acted on them yet, known as suicide ideators $[4,5]$. In order to prevent suicide attempts and reduce suicide rates, the first and foremost is to identify potential population groups who are vulnerable to suicide. However, it is by no means easy, as Franklin et al. claimed in an extensive review of 365 suicide-related studies in the past 50 years [6]. Suicidal thoughts and attempts encompass a wide range of thoughts and behaviors, what's most challenging is to identify the specific thoughts and behaviors closely associated with actual suicides. Note that, there is heavy stigma surrounding suicide, making the highrisk population reluctant to expose themselves. Internet

(c) The Author(s). 2020 Open Access This article is licensed under a Creative Commons Attribution 4.0 International License, which permits use, sharing, adaptation, distribution and reproduction in any medium or format, as long as you give appropriate credit to the original author(s) and the source, provide a link to the Creative Commons licence, and indicate if changes were made. The images or other third party material in this article are included in the article's Creative Commons licence, unless indicated otherwise in a credit line to the material. If material is not included in the article's Creative Commons licence and your intended use is not permitted by statutory regulation or exceeds the permitted use, you will need to obtain permission directly from the copyright holder. To view a copy of this licence, visit http://creativecommons.org/licenses/by/4.0/ The Creative Commons Public Domain Dedication waiver (http://creativecommons.org/publicdomain/zero/1.0/) applies to the data made available in this article, unless otherwise stated in a credit line to the data. 
search provide a way out, and such methods have already been widely used to reveal the potential attitude or behaviors that can hardly be captured using traditional methods [7-10].

While numerous factors have been recognized in affecting suicidal thoughts and behaviors (STB), such as, life stresses, chronic pain and illness, conflict, disaster, violence, losses, et al. [6], the environmental risks have been poorly understood. As a heatedly discussed dimension, air pollution has a detrimental impact on individual health, including higher rates of mortality [11-15], increased incidence of stroke [16], respiratory diseases [17-19], and lung and cardiovascular dysfunction [2026], to name a few. In fact, air pollution has been revealed to be complicit in over 4 million deaths globally since 2015 [27]. Foremost among the pollutants associated with these mortality and morbidity numbers were airborne particulate matter including $\mathrm{PM}_{10}$ and $\mathrm{PM}_{2.5}$ (particles less than 10 or $2.5 \mu \mathrm{m}$ in diameter). As a mixture of fine particles and liquid droplets, $\mathrm{PM}_{2.5}$ is a particular danger because it is easily sucked into the lungs, where it can have a devastating impact on an individual's health.

Previous studies also indicate that $\mathrm{PM}_{2.5}$ and $\mathrm{PM}_{10}$ also have detrimental impact on mental health. For instance, depression has been reported by a bulk of literature to be closely correlated with $\mathrm{PM}_{2.5}$ [28-34]. Importantly, depression is a primary risk factor for suicide [35-38]. Therefore, it is likely that particulate matter such as $\mathrm{PM}_{2.5}$ and $\mathrm{PM}_{10}$ might also influence suicidal ideation. However, results of studies on the link between particulate matter and suicidal behaviors are mixed and mostly from western developed countries [39-42].

Since suicidal ideation is an independent and important risk factor for suicidal behavior [43], quantifying suicidal ideation in a scientific way and examining the ideation-related linkages should be a priority. There is a long chain of causality between particulates and suicidal behavior that begins with a series of shorter but clearer links between suicide-related mechanisms, such as particulate-depression, depression-ideation, particulateideation, depression-behavior, and ideation-behavior, etc. To determine if a relationship between ambient air particulates and suicidal ideation exists, we need to consider whether the variation of particulate matters in our research context (i.e., a given country, a city, or a society) is large enough to allow us to observe the differences that particulates make. This suggests that if findings obtained from industrialized societies are mixed, a more promising way of finding solid evidence is to look into developing countries where air pollution is more rampant.

Therefore, we chose China as the case for study. In the past two decades, China has experienced unprecedented economic growth accompanied by rapidly increasing mental health problems [44] as well as rapidly deteriorating air quality. The latest $\mathrm{PM}_{2.5}$ concentration data collected from the air quality monitoring station in more than 300 cities indicated that the majority of cities fail to meet air quality standards set by WHO [45]. Of note, the Chinese people and governments increasingly concerned with ambient air pollution due to the mass media and citizen watchdogs transmitting news and information about particulate matter (in particular $\mathrm{PM}_{2.5}$ ). Drastic actions have been taken to improve air quality in recent years including shutting down local coal-fired power plants, reducing the production of steel, and limiting driving. Still, the environmental hazard persists and makes China an ideal lab for looking into the potential link between suicidal ideation and ambient air particulates, especially $\mathrm{PM}_{2.5}$.

To quantify the aggregate level of suicidal ideation, we extract from Baidu (the largest online search engine in China) the local volumes of online search queries indicating suicidal thoughts manifested by the presence of plans to commit suicide. In fact, online searches indicating suicidal thoughts are used to quantify suicidal ideation in a recent study published in JAMA [46]. Besides, the closely related suicide-related internet search and suicide rates lend further support to the method of using online searches to measure suicidal ideation [47-50]. Compared with traditional survey methods and clinic processes to detect the extent of suicidal ideation, exploiting internet searching behavior has its unique advantages. Without the presence of a third party, suicide ideators are free to search for relevant information in private, which largely reduced the level of underreporting when using traditional survey method [51, 52]. The ideation-driven search behavior at the individual level aggregates and shapes the local pattern at the collective level. This suggests that in a city or county, the more suicide searches- "how to suicide," "I want suicide," "how to die easily," or different ways to commit suicide-the higher the local suicidal ideation is.

Using this method to measure suicidal ideation, we proceed to examine whether and how local PM2.5 levels are associated with local suicidal ideation in China, based on nationally representative panel data collected from 278 Chinese prefectures in 52 weeks in 2017.

\section{Methods}

\section{Research design}

Using Internet search query volumes in China's largest search engine Baidu and other online environmental data in 2017, we constructed a panel dataset at prefecture-level (278 cities, 52 weeks). In Baidu archives, most frequently searched items (words or short sentences) and the relevant IP locations from these searches were launched. Daily 
frequencies are computed as the Baidu Index. This allows us to access daily/weekly/monthly volumes of suicidalideation-related search queries at the prefecture level. We used Python 2.7.11 software to gather data on all chosen terms, and chose 'week' as the analytic time-frame unit over the course of 2017 because weekly time series are not affected by noise in daily time series and can be used to better identify seasonal and long-term trends of $\mathrm{PM}_{2.5}$ exposure and suicidal ideation.

\section{Index of suicidal ideation (ISI)}

Prefecture-level suicidal ideation, the dependent variable, is gauged by the index of suicidal ideation (ISI) computed using suicide-related search data extracted from Baidu. As for the items signaling suicidal thoughts, we chose most commonly used phrases or short sentences clearly stating an intent to commit suicide. Specifically, we extracted the search volumes for five short sentences: 1) I want suicide (我想自杀); 2) I would like to commit suicide (我要自杀); 3) How to commit suicide (如何自杀); 4) suicidal methods (自杀方法); and 5) methods of suicide (自杀的 方法); together with 11 Chinese words that can be seen as indirect signals of suicidal thoughts, such as various methods of committing suicide, the word suicide itself, and several synonyms. Specifically, these words are: 1) suicide (自杀), 2) wrist cutting (割腕), 3) hang oneself (上 吊), 4) charcoal-burning (烧炭), 5) self-burning (自焚), 6) jump to death (跳楼), 7) cutting one's own throat (自刎), 8) lay on the railway (卧轨), 9) attempt suicide (寻死), 10) suicide (suicide) and 11) Death ends all trouble (一了百 了). The five direct and eleven indirect signal phrases/ words together constitute the list of suicide-related words, based on which, we conduct principle component analysis (PCA). we choose the number of components based on the number of larger than one eigenvalue criteria. The PCA result shows that there is only one component whose eigenvalue is larger than one, in this regard, one principal component can capture most of variation of primary variables. By using regression method, we construct index of suicidal ideation ISI-1.

For a robustness check, we included only the five short phrases and dropped the eleven indirect signals of suicidal thoughts as these words may appear not only in individuals' searches, but in news and fiction, which would overstate the degree of suicidal ideation. Note that there are obviously other phrases and words in Chinese representing suicidal thoughts, but the five we chose are the most searched and archived by Baidu. We perform the aforesaid PCA method to construct ISI-2. The results of PCA can be shown in Table 1 .

\section{$\mathrm{PM}_{2.5}$ and other co-pollutant measures}

The key explanatory variable is a prefecture's weekly average $\mathrm{PM}_{2.5}$ measured at $100 \mu \mathrm{g} \cdot \mathrm{m}^{-3}$ in 2017 , which was

Table 1 Factor loadings of depression search index in Baidu

\begin{tabular}{|c|c|c|c|c|}
\hline Variables & $|S|-1$ & Uniqueness & $|S|-2$ & Uniqueness \\
\hline "I want suicide" & 0.681 & 0.537 & 0.742 & 0.449 \\
\hline "I would like to commit suicide" & 0.415 & 0.828 & 0.498 & 0.752 \\
\hline "How to commit suicide" & 0.695 & 0.518 & 0.741 & 0.451 \\
\hline "Suicidal methods" & 0.67 & 0.551 & 0.731 & 0.465 \\
\hline "Methods of suicide" & 0.661 & 0.564 & 0.728 & 0.471 \\
\hline suicide & 0.768 & 0.41 & & \\
\hline wrist cutting & 0.712 & 0.492 & & \\
\hline hang oneself & 0.709 & 0.498 & & \\
\hline charcoal-burning & 0.556 & 0.691 & & \\
\hline self-burning & 0.453 & 0.795 & & \\
\hline jump to death & 0.733 & 0.463 & & \\
\hline cutting one's own throat & 0.574 & 0.67 & & \\
\hline lay on the railway & 0.543 & 0.706 & & \\
\hline attempt suicide & 0.085 & 0.993 & & \\
\hline suicide (suicide) & 0.769 & 0.408 & & \\
\hline Death ends all trouble & 0.555 & 0.692 & & \\
\hline Eigenvalue & 6.186 & & 2.412 & \\
\hline Variance (\%) & 38.66 & & 48.23 & \\
\hline Cronbach's Alpha & 0.818 & & 0.723 & \\
\hline
\end{tabular}

Note. Principal component factor analysis. For ISI-1, KMO $=0.965$ Bartlett's test of sphericity $=5.23 \mathrm{e}+05(120), p<0.001$. For ISI-2, KMO $=0.799$ Bartlett's test of sphericity $=95,837.689(10), p<0.001$ 
collected from China's Air Quality Online Monitoring and Analysis Platform (https://www.aqistudy.cn/historydata). We also collected the information of weekly average $\mathrm{PM}_{10}, \mathrm{SO}_{2}$, and $\mathrm{NO}_{2}$ from the same source, as various research has shown that these co-pollutants are associated with elevated risk of adverse health outcomes.

\section{Meteorological conditions}

Additionally, the relationship between $\mathrm{PM}_{2.5}$ and suicidal ideation searches is likely to be confounded by timevariant factors. Previous studies that examined the effect $\mathrm{PM}_{2.5}$ on mental disorders and results such as suicide pointed out that confounding meteorological conditions including sunlight, temperature [53, 54], and rain fall should be taken into account [55-57] because these meteorological factors may simultaneously affect suicide risk [51, 58-63] and $\mathrm{PM}_{2.5}$ concentration. We controlled for weekly day mean temperature (Temp), weekly ratio of rainy days (Rain), and adjusted weekly sunlight (Sunlight) measured by the average length of a day in a given week multiplied by the weekly ratio of sunny days in each city over the course of the year. This information was collected from the Chinese website Historical Weather (http://www.tianqihoubao.com/lishi) and Sunrise and Sunset on the website of Convenience Inquiry (https:// mtop.chinaz.com/site_richurimo.51240.com.html).

Given that the imbalanced internet development across regions may potentially influence individuals' search behaviors, we further controlled for city-level frequency of surfing 11 of the most popular and widelyused web portals in China (Webportal). They are 百度 (Baidu), 微信 (We-chat), QQ (qq), 淘宝 (Taobao), 支付 宝 (Alipay), 新浪 (Sina), 搜狐 (Sohu), 网易 (Netease), 腾 讯 (Tencent), 中央电视台 (Chinese Central Television), and 高铁 (Bulliet Strain). To reduce the dimensionality of the data, we conducted principal component analysis and extracted one factor from these items. Moreover, we also controlled for the air pollution search to take into account the regional concern about air pollution. This measure not only reflected the regional population's environmental awareness, but also reflected the media effect on air pollution. The descriptive statistics of key variables are shown in Table 2.

\section{Dynamic panel models}

In this analysis, we take advantage of the panel to control for regional heterogeneity. To capture the dynamic structure of suicide-related searches, we adopted dynamic panel models by introducing the one-week lagged value $(t-1)$ of ISI to specify the path dependence condition. In order to deal with the reversed causality problem, we imposed the temporal order in the models by using the lagged values $(t-1)$ of all explanatory variables. The model can be written as:

$$
\begin{aligned}
I^{S I_{i_{-} t}}= & \alpha I S I_{i_{-}(t-1)}+\beta_{1} P M 2.5_{i_{-}(t-1)} \\
& +\beta_{2} \text { PM10 }_{i_{-}(t-1)}+\beta_{3} \text { SO2 }_{i_{-}(t-1)} \\
& +\beta_{4} \text { NO2 }_{i_{-}(t-1)}+\delta_{1} \text { WebPortal }_{i_{-}(t-1)} \\
& +\delta_{2} \text { PoSearch }_{i_{-}(t-1)}+\delta_{3} \text { Temp }_{i_{-}(t-1)} \\
& +\delta_{4} \text { Rain }_{i_{-}(t-1)}+\delta_{5} \text { Daylength }_{i_{-}(t-1)} \\
& +T_{i}+\mu_{i}+\varepsilon_{i t}
\end{aligned}
$$

In the equation, $I S I_{i_{-} t}$ is the dependent variable, representing the level of suicide searches in city $i$ week $t$, while $I S I_{i_{-}(t-1)}$ is its one-week lagged value. PM2.5 ${i_{-}(t-}_{-}$ 1) is the key independent variable, representing the level

\begin{tabular}{|c|c|c|c|c|c|}
\hline Variable & Description & Mean & S.D. & Min & Max \\
\hline$|S|-1$ & $\begin{array}{l}\text { Index of the suicide ideation measured by search } \\
\text { volumes of indirect signals of suicidal thoughts } \\
\text { from Baidu using PCA method ( } 16 \text { items) }\end{array}$ & 0.016 & 0.967 & -0.640 & 7.224 \\
\hline$|S|-2$ & $\begin{array}{l}\text { Index of the suicidal ideation measured by search } \\
\text { volumes of five short sentences in Chinese from } \\
\text { Baidu using PCA method ( } 5 \text { items) }\end{array}$ & 0.014 & 0.891 & -0.517 & 5.736 \\
\hline PM2.5 & Prefecture's weekly average $P M_{2.5} 100 \mu \mathrm{g} \cdot \mathrm{m}^{-3}$ in 2017 & 0.862 & 0.499 & 0.189 & 8.670 \\
\hline PM10 & Prefecture's weekly average $P M_{10} 100 \mu \mathrm{g} \cdot \mathrm{m}^{-3}$ in 2017 & 5.416 & 3.120 & 0.330 & 44.460 \\
\hline $\mathrm{SO} 2$ & Prefecture's weekly average $\mathrm{SO}_{2} 100 \mu \mathrm{g} \cdot \mathrm{m}^{-3}$ in 2017 & 1.224 & 1.159 & 0.020 & 19.480 \\
\hline $\mathrm{NO} 2$ & Prefecture's weekly average $\mathrm{NO}_{2} 100 \mu \mathrm{g} \cdot \mathrm{m}^{-3}$ in 2017 & 2.092 & 1.018 & 0.120 & 6.860 \\
\hline WebPortal & Frequency of surfing Chinese major web portal & 0.019 & 1.010 & -0.933 & 11.408 \\
\hline PoSearch & Frequency of searching air pollution related items & 0.019 & 0.889 & -0.840 & 32.592 \\
\hline Temp & Weekly averaged day mean temperature & 15.897 & 10.582 & -23.900 & 34.786 \\
\hline Rain & Weekly ratio of rainy days (Rain) & 0.265 & 0.243 & 0.000 & 1.000 \\
\hline Sunlight & Weekly sunlight & 23.067 & 21.164 & 0.000 & 105.441 \\
\hline
\end{tabular}
of weekly average $P M_{2.5}$ in city $i$ week $t-1$. Considering the potential confounding from other co-pollutants and meteorological variables, we include one-week lag of $P M_{10}, S_{2}, N O_{2}$, temperature (Temp), rainy day ratio

Table 2 Descriptive Statistics of Major Variables 
(Rain), weekly sunlight (Daylength) in city $i$. Moreover, to adjust for the different level of internet development and pollution concern across cities, one-week lag of frequency of searching air pollution related items (WebPortal) and frequency of searching air pollution related items (PollutionSearch) are also included in the Eq. (1). As shown, $\beta_{i}$ and $\delta_{i}$ are the coefficients of the corresponding variables. $T_{i}$ is the week-specific trend of suicidal ideation. $\mu_{i}$ is the city-level time constant error term, and $\varepsilon_{i t}$ is the city-level time-varying error term.

We employed System Generalized Method of Moments (SGMM) estimator to examine the association between $\mathrm{PM}_{2.5}$ and suicidal searches for three reasons. First, SGMM can rule out the impact of city-level heterogeneity in time-constant factors like fixed-effects models. Second, it can deal with the potential endogeneity problem by using appropriate lagged dependent and independent variable as "internal" instrumental variables. Third, by including the equations in both first-difference and levels $[64,65]$, we can downgrade the influence of measurement errors to a large degree [66]. We have conducted several diagnostic tests to check the validity of SGMM estimators. Specifically, we have performed: (1) the unit-root test and assure that all variables are stationary time series; (2) AR (2) test to check whether $\mu_{i t}$ are serially correlated $(p>0.05)$; and (3) the Henson/Sargan over-identification test to examine the validity of these instruments $(p>0.05)$. Overall, the results of these tests suggest that SGMM is a valid estimator in this study.

\section{Results}

\section{The trend of PM2.5 and ISI}

Table 2 presents descriptive statistics for key variables in this study and shows the average $\mathrm{PM}_{2.5}$ level of all 278 cities over the course of the year was around $86.2 \mu \mathrm{g} \cdot \mathrm{m}^{-}$ ${ }^{3}$. To show the distribution of $\mathrm{PM}_{2.5}$ and ISI across cities, we draw Fig. 1. As revealed, there was considerable regional variation in $\mathrm{PM}_{2.5}$ and ISI, and both varied seasonally as well. There is an elevated $\mathrm{PM}_{2.5}$ concentration in central China and some parts of northeast and northwest China where heavy industry abounds. However, in western, south and some parts of northeast and China where service industries prevail, $\mathrm{PM}_{2.5}$ concentration is relatively low. In terms of changes in $\mathrm{PM}_{2.5}$ concentration throughout the year, we observed a higher level of PM2.5 in winter than in other seasons. We also observed a larger variation in PM2.5 in northwest China relative to the rest of China, where a continental rather than a monsoon climate is dominant.

Table 2 also shows that average suicidal ideation of all 278 cities in 2017 was 0.016 . The time series of provincial ISI is further drawn in Fig. 1. ISI is higher in most coastal areas, where internet use is more common. In some parts of Sichuan and northern Xinjiang, ISI is also high. This may be relevant to the high out-migration rate that leaves a large amount of left-over elderly, and children in that area. With regard to time trend, it is clear that, despite some seasonal changes, the variation of ISI is much smaller compared to $\mathrm{PM}_{2.5}$.

\section{Model results}

In Table 3, we present model results of ISI-1, the measure of suicidal ideation by extracting the suicidal intention from five short phrases/sentences. The oneweek lag of ISI is positive at the 0.001 significance level, meaning that ISI is the path dependent as expected. Web-Portal shows a significantly positive effect on ISI throughout the year. However, $\mathrm{PM}_{2.5}$ does not seem to significantly predict ISI. Given that the mixture of particulate matter varies by season, we further look into the effects across seasons.

The by-season results clearly show that, $\mathrm{SO}_{2}$ and $\mathrm{NO}_{2}$ do not exert significant impacts on ISI throughout the year. $\mathrm{PM}_{2.5}$ can positively predict ISI in spring and winter, even when taking account co-pollutants, and other weather conditions (e.g., temperature, rainfall, sunlight), regional internet usage, and pollution concerns. A $10 \mu \mathrm{g} \cdot \mathrm{m}-3$ increase in $\mathrm{PM}_{2.5}$ is associated with a 0.020 increase of ISI in spring and a 0.007 increase in winter. Though $\mathrm{PM}_{10}$ also shows significant positive effect in spring, the effect is much smaller, merely $1 / 7$ of $\mathrm{PM}_{2.5}$.

As a robustness check, we follow the same modelbuilding strategy and take ISI-2, the measure of suicidal ideation, using more extended search items relevant to suicide as the dependent variable in Table 4 . The results are consistent and only vary in the magnitude. Overall, this confirms that our results are robust regardless of measurement of ISI.

\section{Discussion}

Suicide is a global public health threat. Despite its importance, much remains unknown about the risk factors behind suicidal thoughts and behaviors. Some researchers blamed this to a lack of reliable STB indicators, leading to the slow progress and low effectiveness of suicide interventions [2, 43, 67]. In this study, to capture the potential suicide attempt, we take advantage of internet search data, a new method to measure the potential concern, or psychological tendency which cannot be captured in a traditional way.

In the past decades, numerous attempts have been made to establish risk factors of suicidal thoughts and behaviors, encompassing biological, psychological, and sociological factors [68-70], whether environmental factor is associated with suicidal thoughts and behaviors remain scare. Recent scholarship has shown that air pollution, specifically $\mathrm{PM}_{2.5}$, is a factor in depression. Suicidal ideation, a 


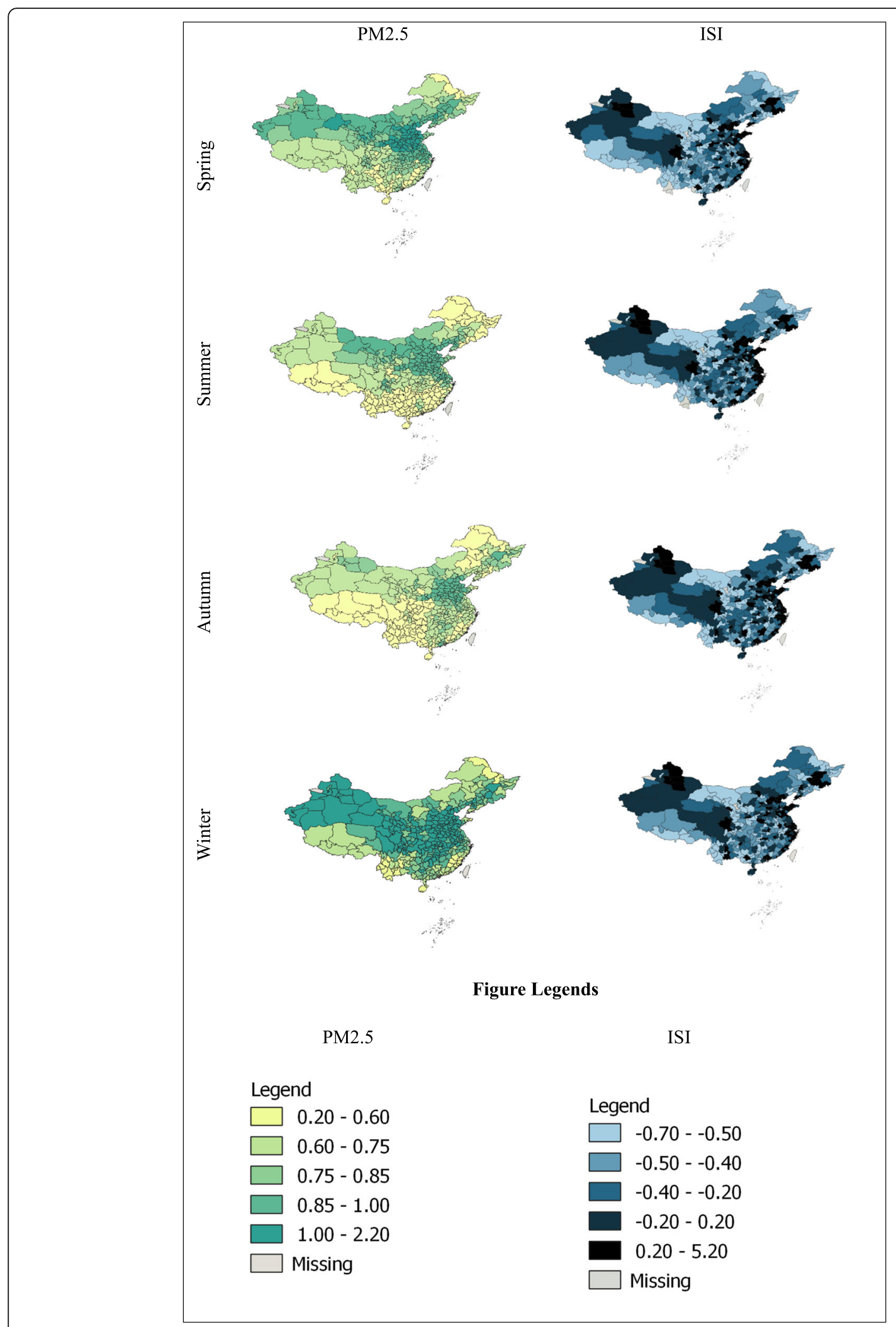

Fig. 1 Weekly $\mathrm{PM}_{2.5}$ level and ISI in Chinese cities by season (2017). Note: The maps are generated using QGIS 
Table 3 SGMM predicting suicidal ideation by season using ISI-1

\begin{tabular}{|c|c|c|c|c|c|}
\hline & All & Spring & Summer & Autumn & Winter \\
\hline \multirow[t]{2}{*}{ Lagged ISII } & $0.334^{* *}$ & $0.198^{* * * *}$ & 0.026 & 0.169 & $0.343^{* * *}$ \\
\hline & $(0.102)$ & $(0.031)$ & $(0.104)$ & $(0.243)$ & $(0.040)$ \\
\hline \multirow[t]{2}{*}{ PM2.5 } & 0.071 & $0.196^{* * *}$ & -0.047 & -0.044 & $0.069^{*}$ \\
\hline & $(0.074)$ & $(0.032)$ & (0.138) & $(0.292)$ & $(0.033)$ \\
\hline \multirow[t]{2}{*}{ PM10 } & 0.002 & $0.014^{* * *}$ & -0.002 & -0.007 & 0.001 \\
\hline & $(0.011)$ & $(0.003)$ & $(0.015)$ & $(0.045)$ & $(0.004)$ \\
\hline \multirow[t]{2}{*}{$\mathrm{SO} 2$} & -0.009 & $0.068^{* *}$ & -0.029 & 0.044 & -0.010 \\
\hline & $(0.103)$ & $(0.022)$ & $(0.111)$ & $(0.105)$ & $(0.019)$ \\
\hline \multirow[t]{2}{*}{$\mathrm{NO} 2$} & 0.090 & $0.069^{*}$ & -0.001 & 0.022 & $0.134^{* * *}$ \\
\hline & $(0.069)$ & $(0.027)$ & (0.089) & $(0.203)$ & $(0.021)$ \\
\hline \multirow[t]{2}{*}{ WebPortal } & 0.338 & 0.131 & $0.448^{*}$ & $0.457 \dagger$ & $0.273^{* * *}$ \\
\hline & $(0.293)$ & $(0.107)$ & (0.190) & $(0.236)$ & $(0.062)$ \\
\hline \multirow[t]{2}{*}{ PoSearch } & 0.016 & $0.312^{* *}$ & 0.174 & 0.144 & $-0.022 \dagger$ \\
\hline & $(0.049)$ & $(0.098)$ & $(0.222)$ & $(0.175)$ & $(0.012)$ \\
\hline \multirow[t]{2}{*}{ Temp } & 0.003 & $0.009^{* * * *}$ & $0.014^{*}$ & 0.004 & $0.022^{* * *}$ \\
\hline & $(0.004)$ & $(0.002)$ & $(0.006)$ & $(0.003)$ & $(0.003)$ \\
\hline \multirow[t]{2}{*}{ Rain } & -0.000 & 0.000 & -0.000 & 0.000 & $-0.002^{+}$ \\
\hline & $(0.001)$ & $(0.000)$ & $(0.000)$ & $(0.001)$ & $(0.001)$ \\
\hline \multirow[t]{2}{*}{ Sunlight } & -0.001 & $-0.001^{*}$ & 0.000 & -0.000 & 0.000 \\
\hline & $(0.001)$ & $(0.000)$ & $(0.001)$ & $(0.003)$ & $(0.001)$ \\
\hline $\mathrm{N}$ & 13,881 & 3539 & 3528 & 3544 & 1370 \\
\hline chi2 & 1766.110 & 450.296 & 301.061 & 310.205 & 447.354 \\
\hline
\end{tabular}

Note. Numbers in parentheses are robust standard errors. ${ }^{* *} p<0.001,{ }^{* *} p<$ $0.01,{ }^{*} p<0.05,+p<0.1$

symptom of major depression is thus likely to be influenced by $\mathrm{PM}_{2.5}$. To explore such correlates, this research examines the potential link between $\mathrm{PM}_{2.5}$ and suicide ideation based on the context of China. The country has experienced rapid industrialization and modernization accompanied by an increase in mental health problems as well as environmental problems, where air pollution continues to pose a serious and sustained threat to residents physical and mental health.

We constructed a weekly index of suicidal ideation (ISI) in 278 major cities in China using internet searches that indicated suicide thoughts on Baidu, the most widely used search engine in China. The internet-based method of quantifying suicidal ideation allowed us to proxy the local level of thinking about suicide, which is often concealed, fleeting, and not easy to identify using traditional means. The SGMM estimators revealed that the effect of $\mathrm{PM}_{2.5}$ on suicidal ideation varies by season. A higher concentration of $\mathrm{PM}_{2.5}$ predicted a higher level of suicidal ideation in spring and winter, with ISI increasing for 0.020 in spring and 0.007 in winter for every $10 \mu \mathrm{g} \cdot \mathrm{m}-3$ increase in PM2.5, holding constant of other co-pollutants and meteorological variables. For the rest of the year, $\mathrm{PM}_{2.5}$ did
Table 4 SGMM predicting suicidal ideation by season using ISI-2

\begin{tabular}{|c|c|c|c|c|c|}
\hline & All & Spring & Summer & Autumn & Winter \\
\hline \multirow[t]{2}{*}{ Lagged ISI1 } & $0.488^{* * *}$ & $0.174^{* * *}$ & 0.032 & 0.433 & $0.384^{* * *}$ \\
\hline & $(0.083)$ & $(0.032)$ & $(0.086)$ & $(0.306)$ & $(0.039)$ \\
\hline \multirow[t]{2}{*}{ PM2.5 } & 0.076 & $0.286^{* * *}$ & -0.024 & -0.069 & $0.151^{* * *}$ \\
\hline & $(0.076)$ & $(0.038)$ & $(0.049)$ & $(0.263)$ & $(0.038)$ \\
\hline \multirow[t]{2}{*}{ PM10 } & 0.008 & $0.040^{* * *}$ & -0.014 & -0.001 & -0.010 \\
\hline & $(0.032)$ & $(0.007)$ & $(0.044)$ & $(0.129)$ & $(0.015)$ \\
\hline \multirow[t]{2}{*}{$\mathrm{SO} 2$} & -0.021 & -0.045 & -0.148 & 0.074 & -0.025 \\
\hline & $(0.142)$ & $(0.074)$ & $(0.423)$ & $(0.210)$ & $(0.053)$ \\
\hline \multirow[t]{2}{*}{ NO2 } & 0.083 & $0.168^{* *}$ & 0.104 & -0.019 & $0.256^{* * *}$ \\
\hline & $(0.174)$ & $(0.064)$ & $(0.349)$ & $(0.347)$ & $(0.037)$ \\
\hline \multirow[t]{2}{*}{ WebPortal } & $0.215^{*}$ & -0.022 & $0.426^{*}$ & 0.306 & 0.048 \\
\hline & $(0.098)$ & $(0.156)$ & $(0.177)$ & $(0.287)$ & $(0.070)$ \\
\hline \multirow[t]{2}{*}{ PoSearch } & 0.012 & $0.223^{* *}$ & $0.258^{*}$ & 0.069 & $-0.017^{*}$ \\
\hline & $(0.039)$ & $(0.082)$ & $(0.125)$ & $(0.230)$ & $(0.007)$ \\
\hline \multirow[t]{2}{*}{ Temp } & 0.003 & $0.010^{* * *}$ & $0.011^{* *}$ & 0.005 & $0.010^{*}$ \\
\hline & $(0.004)$ & $(0.003)$ & $(0.004)$ & $(0.004)$ & $(0.004)$ \\
\hline \multirow[t]{2}{*}{ Rain } & 0.000 & 0.000 & -0.000 & -0.000 & -0.000 \\
\hline & $(0.000)$ & $(0.000)$ & $(0.000)$ & $(0.002)$ & $(0.001)$ \\
\hline \multirow[t]{2}{*}{ Sunlight } & $-0.002+$ & $-0.002^{* * *}$ & -0.000 & -0.000 & $-0.002^{* * *}$ \\
\hline & $(0.001)$ & $(0.000)$ & $(0.001)$ & $(0.002)$ & $(0.001)$ \\
\hline N & 13,830 & 3526 & 3515 & 3531 & 3258 \\
\hline chi2 & 3228.240 & 279.557 & 469.719 & 550.914 & 747.642 \\
\hline
\end{tabular}

Note. Numbers in parentheses are robust standard errors. ${ }^{* * *} p<0.001,{ }^{* *} p<$ $0.01, * 0<0.05,+p<0.1$

not show a significant effect. This result, to some degree, echoes the findings of depressive symptoms [71], where the peak prevalence of depression is usually discovered in winter [72-77] or spring $[78,79]$.

Overall, our study shows a significant and substantial positive relation between $\mathrm{PM}_{2.5}$ and suicidal ideation, contributing to the literature not only by shedding more light on our understanding of the pollution-suicide link but also by providing a scientific method to quantify suicidal ideation using online big data.

\section{Limitations and strengths}

Our research has several limitations. First, due to stigmatization, individuals who are thinking of committing suicide incline to hide their true feelings, and often, they may express such inclination in a subtler and less straightforward way. In this vein, we may overlook some relevant searches that can signal suicidal thinking and behaviors. However, there are a wide range of thoughts and behaviors in suicidal thoughts and behaviors: thinking about suicide, developing a plan, obtaining the relevant tools. Only the last stage reflects a serious intention that may turn to physical action. In this vein, the search 
items we designed for this analysis captured intention to a large degree. Second, due to weekly changes in social, economic, and political conditions in each city, we may have ignored economic crisis, social conflict, or political hurdles that influenced suicide ideation. However, our analysis is based on weekly information in only 1 year, meaning that we focus on the short-term, rather than long-term impact of $\mathrm{PM}_{2.5}$. In this vein, assuming no short-term change of social, economic, and political conditions is plausible. Third, due to the lack of relevant clinical data, we cannot the identify the mechanism to establish the PM2.5-suicidal ideation link across seasons. However, as documented in various other research, the larger effect of $\mathrm{PM}_{2.5}$ in winter and spring is likely to be attributed to inflammation and oxidative stress [80-83], from high-emission of vehicle, biomass and coal combustion [84-88], for which, we will take it as a future direction to work on.

Despite these drawbacks, our research is an innovative attempt to quantify suicide ideation and reveal the potential linkage between $\mathrm{PM}_{2.5}$ and suicidal ideation. Our study shows a significant positive relationship between $\mathrm{PM}_{2.5}$ and ISI, contributing to the literature not only by shedding more light on our understanding of the pollution-suicide link but also by providing a new method to quantify suicide ideation using big data. The present environmental degradation and pollution is a product of rapid, unbridled industrialization. Amid public outcry over record-high pollution levels, researchers face a pressing urgency to understand how these pollutants are associated with physical and mental health risks.

\section{Conclusion}

There is heavy stigma associated with suicide, making suicidal ideation a hidden pain. To reveal suicidal ideation as accurately as we can, we resort internet search data to construct a prefecture-level weekly index of suicidal ideation (ISI). By using this innovative measure, the present study examined the association between $\mathrm{PM}_{2.5}$ and ISI, and showed how such association would vary by season. Although future studies are still needed to explore specific mechanisms. Our findings might be taken as a reference for suicide prevention.

\section{Abbreviation}

ISI: Weekly index of suicidal ideation

\section{Authors' contributions}

YC and GH conceived and designed the study. BC and TG helped to collect the data and provided the suggestions in interpreting the findings. SW, GH, and $\mathrm{GJ}$ conducted the data analysis. YC, GH and SW prepared the first draft of the manuscript. YC, GH, BC, SW, GJ and TG helped to revise the paper. All authors read the final version of the manuscript and approved to submission.

\section{Funding}

The authors acknowledge the support by grants from Major Project of the National Social Science Fund of China (No:19ZDA149) and National Natural Science Foundation of China (71921003).

Availability of data and materials

All data are available from the authors.

Ethics approval and consent to participate

Not applicable.

\section{Consent for publication}

Not applicable. This analysis is based on search engine data at province level, no individual information is required.

\section{Competing interests}

The authors declare that they have no competing interests.

\section{Author details}

${ }^{1} J o h n s$ Hopkins University-Nanjing University Center for Chinese and American Studies, Gulou District, Nanjing 210093, China. ${ }^{2}$ School of Social and Behavioral Sciences, Nanjing University, 163 Xianlin Road, Qixia District, Nanjing 210023, China. ${ }^{3}$ The First Affiliated Hospital with Nanjing Medical University, Nanjing 210029, China. ${ }^{4}$ The University of Cambridge, 16 Mill Lane, Cambridge CB2 1SB, UK.

Received: 22 July 2019 Accepted: 25 February 2020

Published online: 06 March 2020

\section{References}

1. World Health Organization. Preventing suicide: a global imperative. Geneva: WHO Press; 2017. retrieved from: http://apps.who.int/iris/bitstream/1 0665/131056/1/9789241564779_eng.pdf?ua=1.

2. Nock MK, Borges G, Bromet EJ, Cha CB, Kessler RC, et al. Suicide and suicidal behavior. Epidemiol Rev. 2008;6030:133-54. https://doi.org/10.1093/epirev/ $\mathrm{m} \times n 002$.

3. Crosby AE, Han B, Ortega LA, Parks SE, Gfroerer J, et al. Suicidal thoughts and behaviors among adults aged $\geq 18$ years --- United States, 2008-2009. MMWR Surveill Summ. 2011;60(SS13):1-22.

4. Borges G, Angst J, Nock MK, Ruscio AM, Kessler RC. Risk factors for the incidence and recurrence of suicide-related outcomes: A 10-year follow-up study using the National Comorbidity Surveys. J Affect Disord. 2008;105:2533.

5. Klonsky ED, May AE. Differentiating suicide attempters from suicide ideators: a critical frontier for suicidology research. Suicide Life Threat Behav. 2014; 44(1):1-5.

6. Franklin JC, Ribeiro JD, Fox KR, Bentley KH, Kleiman EM, Huang X, et al. Risk factors for suicidal thoughts and behaviors: a meta-analysis of 50 years of research. Psychol Bull. 2017;143(2):187-232.

7. Bentley RA, Acerbi A, Ormerod P, et al. Books average previous decade of economic misery. PLoS One. 2014;9(1):e83147.

8. Chen Y, Yan F. Economic performance and public concerns about social class in twentieth-century books. Soc Sci Res. 2016:59:37-51.

9. Chen $Y$, Yan F. International visibility as determinants of foreign direct investment: an empirical study of Chinese provinces. Soc Sci Res. 2018;76: 23-39.

10. Chen Y, Yan F, Zhang Y. Local name, global fame: the international visibility of Chinese cities in modern times. Urban Stud. 2017:1-17.

11. Chen $Y$, Ebenstein A, Greenstone M, Li H. Evidence on the impact of sustained exposure to air pollution on life expectancy from China's Huai River policy. Proc Natl Acad Sci U S A. 2013;110:12936-41.

12. Ebenstein A, Fan M, Greenstone M, He G, Zhou M. New evidence on the impact of sustained exposure to air pollution on life expectancy from China's Huai River policy. Proc Natl Acad Sci U S A. 2017;114:10384-9.

13. He G, Fan M, Zhou M. The effect of air pollution on mortality in China: evidence from the 2008 Beijing Olympic games. J Environ Econ Manag. 2016;79:18-39.

14. Heinrich J, Thiering E, Rzehak P, Krämer U, Hochadel M, Rauchfuss KM, et al. Long-term exposure to $\mathrm{NO}_{2}$ and $\mathrm{PM}_{10}$ and all-cause and cause-specific mortality in a prospective cohort of women. Occup Environ Med. 2013;70: 70179-86. 
15. Kelly FJ, Fussell JC. Air pollution and public health: emerging hazards and improved understanding of risk. Environ Geochem Health. 2015;37:631-49.

16. Wellenius GA, Schwartz J, Mittleman MA. Air pollution and hospital admissions for ischemic and hemorrhagic stroke among Medicare beneficiaries. Stroke. 2005;36:2549-53.

17. Adam M, Schikowski T, Carsin AE, Cai Y, Jacquemin B, Sanchez M, et al. Adult lung function and long-term air pollution exposure. ESCAPE: a multiCentre cohort study and meta-analysis. Eur Respir J. 2015;45:38-50. https:// doi.org/10.1183/09031936.00130014.

18. Kim K, Jahan SA, Kabir E. A review on human health perspective of air pollution with respect to allergies and asthma. Environ Int. 2013;59:41-52.

19. Schikowski T, Adam M, Marcon A, Cai Y, Vierkotter A, et al. Association of ambient air pollution with the prevalence and incidence of COPD. Eur Respir J. 2014;44:614-26.

20. Gallagher P, Lazarus W, Shapouri H, Conway R, Bachewe F, Fischer A. Cardiovascular disease_risk benefits of clean fuel technology and policy: a statistical analysis. Energ Policy. 2010:38:1210.

21. Beelen R, Stafoggia M, Raaschou-Nielsen O, Andersen ZJ, Xun WW, Katsouyanni K, et al. Long-term exposure to air pollution and cardiovascular mortality: an analysis of 22 European cohorts. Epidemiology. 2014;25(3):368-78.

22. Peters A, Pope CA. Cardiopulmonary mortality and air pollution. Lancet. 2002;360:1184-5

23. Pope CA, Burnett RT, Thun MJ, Calle EE, Krewski D, Ito K, Thurston GD. Lung cancer, cardiopulmonary mortality, and long-term exposure to fine particulate air pollution. JAMA. 2002;287:1132-41.

24. Pope CA, Burnett RT, Thurston GD, Thun MJ, Calle EE, Krewski D, Godleski JJ. Cardiovascular mortality and long-term exposure to particulate air pollution-epidemiological evidence of general pathophysiological pathways of disease. Circulation. 2004;109:71-7.

25. Sorensen M, Hoffmann B, Hvidberg M, Ketzel M, Jensen SS, Andersen ZJ, et al. Long-term exposure to traffic-related air pollution associated with blood pressure and self-reported hypertension in a Danish cohort. Environ Health Perspect. 2012;120:418-24

26. Wang Y, Eliot MN, Koutrakis P, Gryparis A, Schwartz JD, Coull BA, Mittleman MA, Milberg WP, Lipsitz LA, Wellenius GA. Ambient air pollution and depressive symptoms in older adults: results from the MOBILIZE Boston study. Environ Health Perspect. 2014;122:553-8.

27. Cohen AJ, Brauer M, Burnett R, Anderson HR, Frostad J, Estep K, et al. Estimates and 25-year trends of the global burden of disease attributable to ambient air pollution: an analysis of data from the global burden of diseases study 2015. Lancet. 2017;389(10082):1907-18.

28. Buoli M, Grassi S, Caldiroli A, Carnevali GS, Mucci F, lodice S, et al. Is there a link between air pollution and mental disorder? Environ Int. 2018;118:154-68.

29. Kim K, Lim Y, Bae HJ, Kim M, Jung K, Hong Y. Long-term fine particulate matter exposure and major depressive disorder in a community-based urban cohort. Environ Health Perspect. 2016;124:1547-53.

30. Szyszkowicz M. Air pollution and emergency department visits for depression in Edmonton, Canada. Int J Occup Med Environ Health. 2007; 20(3):241-5.

31. Vert C, Sanchez-Benavides G, Martinez D, Gotsens X, Gramunt N, Cirach M, ... , Gascon M. Effect of long-term exposure to air pollution on anxiety and depression in adults: A cross-sectional study. Int J Hyg Environ Health. 2017; 220:1074-1080.

32. Wang $R$, Xue D, Liu Y, Liu P, Chen $H$. The relationship between air pollution and depression in China: is neighbourhood social capital protective? Int J Environ Res Public Health. 2018;15:1160.

33. Yin $\mathrm{H}$, Pizzol M, Jacobsen JB, Xu L. Contingent valuation of health and mood impacts of PM2.5 in Beijing, China. Sci Total Environ. 2018;630:1269-82.

34. Zhang $X$, Zhang $X$, Chen $X$. Happiness in the air: how does a dirty sky affect mental health and subjective well-being. J Environ Econ Manag. 2017;85: 81-94.

35. Angst J, Angst F, Stassen H. Suicide Risk in patients with major depressive disorder. J Clin Psychiatry. 1999;60(supl.2):57-62.

36. Gaynes BN, West SL, Ford CA, et al. Screening for suicide risk in adults: a summary of the evidence for the U.S. preventive services task force. Ann Intern Med. 2004;140:822-35.

37. Reeves A. Working with risk in Counselling and psychotherapy. Newbury Park: SAGE Publications Limited; 2015. http://dx.doi.org/10.4135/9781473916 890 .

38. Tondo L, Isacsson G, Baldessarini R. Suicidal behaviour in bipolar disorder: risk and prevention. CNS Drugs. 2003;17(7):491-511.
39. Fernández-Niño JA, Astudillo-García Cl, Rodríguez-Villamizar LA, Florez-Garcia VA. Association between air pollution and suicide: a time series analysis in four Colombian cities. Environ Health. 2018;17:47.

40. Kim C, Sang HJ, Dae RK, et al. Ambient particulate matter as a risk factor for suicide. Amer J Psychiatry. 2010;167(9):1100-7. https://doi.org/10.1176/appi. ajp.2010.09050706

41. Kim Y, Myung W, Won HH, Shim S, Jeon HJ, Choi J, et al. Association between air pollution and suicide in South Korea: a nationwide study. PLoS One. 2015;10(2):e0117929.

42. Lin GZ, Li L, Song YF. The impact of ambient air pollution on suicide mortality: A case-crossover study in Guangzhou, China. Environ Health. 2016;15(1):90. https://doi.org/10.1186/s12940-016-0177-1.

43. Institute of Medicine (US) Board on Neuroscience and Behavioral Health. Risk Factors For Suicide: Summary of a Workshop. Washington (DC): National Academies Press (US); 2001. retrieved from: https://www.ncbi.nlm. nih.gov/books/NBK223747/.

44. Graham C, Zhou S, Zhang J. Happiness and health in China: the paradox of Progress. Brookings Institution Working Paper; 2015.

45. Lin $Y$, Zou J, Yang W, Li CQ. A review of recent advances in research on PM2.5 in China. Int J Environ Res Public Health. 2018;15:e438.

46. Ayers JW, Althouse BM, Leas EC, Dredze M, Allem JP. Internet searches for suicide following the release of 13 reasons why. JAMA Intern Med. 2017; 177(10):1527-9.

47. Adler N, Cattuto C, Kalimeri K, Paolotti D, Tizzoni M, Verhulst S, Yom-Tov E, Young $\mathrm{A}$. How search engine data enhance the understanding of determinants of suicide in India and inform prevention: observational study. Jed Internet Res. 2019;21(1):e10179.

48. Gunn JF, Lester D. Using Google searches on the internet to monitor suicidal behavior. J Affect Disord. 2013;148(2-3):411-2.

49. Chandler V. Google and suicides: what can we learn about the use of internet to prevent suicides? Public Health. 2018;154:144-50.

50. Yang AC, Tsai SJ, Huang NE, Peng CK. Association of Internet search trends with suicide death in Taipei City, Taiwan, 2004-2009. J Affect Disord. 2011; 132(1-2):179-84.

51. Bell JE, Brown CL, Conlon K, Herring S, Kunkel KE, Lawrimore J, et al. Changes in extreme events and the potential impacts on human health. J Air Waste Manag Assoc. 2018;68(4):265-87.

52. Hunt MG, Auriemma J, Cashaw ACA. Self-report Bias and underreporting of depression on the BDI-II. J Pers Assess. 2003;80:26-30.

53. Holopainen J, Helama S, Bjorkenstam C, Partonen T. Variation and seasonal patterns of suicide mortality in Finland and Sweden since the 1750s. Environ Health Prev Med. 2013;18(6):494-501.

54. Woo J, Okusaga O, Postolache TT. Seasonality of suicidal behavior. Int J Environ Res Public Health. 2012;9(2):531-47.

55. Hales S, Salmond C, Kjellstrom T, Woodward A. Daily mortality in relation to weather and air pollution in Christchurch, New Zealand. Aust N Z J Public Health. 2000:24:89-91.

56. Hsu WH, Hwang SA, Kinney PL, Lin S. Seasonal and temperature modifications of the association between fine particulate air pollution and cardiovascular hospitalization in New York state. Sci Total Environ. 2017:578: 626-32.

57. Samet J, Zeger S, Kelsall J, Xu J, Kalkstein L. Does weather confound or modify the association of particulate air pollution with mortality? Environ Res. 1998;77:7-19.

58. Jacob DJ, Winner DA. Effect of climate change on air quality. Atmos Environ. 2009:43:51-63.

59. Kinney PL. Climate change, air quality, and human health. Am J Prev Med. 2008;35:459-67.

60. Ren C, Williams GM, Tong S. Does particulate matter modify the association between temperature and cardiorespiratory diseases? Environ Health Perspect. 2006;114:1690-6.

61. Tai A, Mickley L, Jacob D. Correlations between fine particulate matter (PM2. 5) and meteorological variables in the United State: implications for the sensitivity of PM2.5 to climate change. Atmos Environ. 2010:44:3976-84.

62. Arellano M, Bond S. Some tests of specification for panel data: Monte Carlo evidence and an application to employment equations. Rev Econ Stud. 1991;58(2):277-97.

63. Holtz-Eakin D, Newey W, Rosen HS. Estimating vector autoregressions with panel data. Econometrica. 1988;56:1371-96.

64. Arellano M, Bover $\mathrm{O}$. Another look at the instrumental variable estimation of error-components models. J Econ. 1995;68(1):29-51. 
65. Blundell $\mathrm{R}$, Bond S. Initial conditions and moment restrictions in dynamic panel data models. J Econ. 1998;87(1):115-43.

66. Griliches Z, Hausman JA. Errors in variables in panel data. J Econ. 1986;31: 93-118.

67. Mars B, Burrows S, Hjelmel H, Gunnell D. Suicidal behavior across the African continent: a review of the literature. BMC Public Health. 2014;14(1):606.

68. Durkheim E. [Suicide: A Study in Sociology]. Le suicide: étude de sociologie. Paris: F. Alcan; 1897

69. Schneider B, Lukaschek K, Baumert J, Meisinger C, Erazo N, Ladwig KH. Living alone, obesity, and smoking increase risk for suicide independently of depressive mood findings from the population-based MONICA/KORA Augsburg cohort study. J Affect Disord. 2014;152:416-21. https://doi.org/10. 1016/j.jad.2013.10.007.

70. Shneidman ES. Suicide as psychache: a clinical approach to self-destructive behavior. New York: Aronson; 1993.

71. Gu X, Liu Q, Deng F, Wang X, Lin H, Guo X, et al. Association between particulate matter air pollution and risk of depression and suicide: systematic review and meta-analysis. Br J Psychiatry. 2019;215:456-67. https://doi.org/10.1192/bjp.2018.295.

72. Harmatz MG, Well AD, Overtree CE, Kawamura KY, Rosal M, Ockene IS. Seasonal variation of depression and other moods: a longitudinal approach. J Biol Rhythm. 2000;15:344-50.

73. Magnusson A. An overview of epidemiological studies on seasonal affective disorder. Acta Psychiatr Scand. 2000;101:176-84.

74. Morken G, Lilleeng S, Linaker OM. Seasonal variation in suicides and in admisisons to hospital for mania and depression. J Affect Disord. 2002;69: 39-45.

75. Murase S, Kitabatake M, Yamauchi T, Mathe AA. Seasonal mood variation among Japanese residents of Stockholm. Acta Psychiatr Scand. 1995;92:51-5.

76. Nayyar K, Cochrane R. Seasonal changes in affective state measured prospectively and retrospectively. Br J Psychiatry. 1996;168:627-32.

77. Oyane NM, Bjelland I, Pallesen S, Holsten F, Bjorvatn B. Seasonality is associatd with anxiety and depression: the Hordaland health study. J Affect Disord. 2008;105:147-55.

78. Nayha S, Vaisanen E, Hassi J. Season and mental illness in an Arctic area of northern Finland. Acta Psychiatr Scand Suppl. 1994;377:46-9.

79. Stordal E, Morken G, Mykletun A, Neckelmann D, Dahl AA. Monthly variation in prevalence rates of comorbid depression and anxiety in the general population at 63-65 degrees north: the HUNT study. J Affect Disord. 2008; 106:273-8.

80. Anisman H, Hayley S. Inflammatory factors contribute to depression and its comorbid conditions. Sci Signal. 2012;5:pe45.

81. MohanKumar SM, Campbell A, Block M, Veronesi B. Particulate matter, oxidative stress and neurotoxicity. Neurotoxicology. 2008;29:479-88.

82. Calderón-Garcidueñas L, Maronpot RR, Torres-Jardon R, Henríquez-Roldán C, Schoonhoven R, Acuña-Ayala $\mathrm{H}$, et al. DNA damage in nasal and brain tissues of canines exposed to air pollutants is associated with evidence of chronic brain inflammation and neurodegeneration. Toxicol Pathol. 2003;31: 524-38.

83. Campbell A, Oldham M, Becaria A, Bondy SC, Meacher D, Sioutas C, et al. Particulate matter in polluted air may increase biomarkers of inflammation in mouse brain. Neurotoxicology. 2005;26:133-40.

84. Fan XC, Lang JL, Cheng SY, Wang XQ, Lü Z. Seasonal variation and source analysis of PM2.5, PM1 and their carbonaceous components in Beijing. Huan Jing Ke Xue. 2018:39:4430-8 [in Chinese].

85. Gu Y, Yim SHL. The air quality and health impacts of domestic transboundary pollution in various regions of China. Environ Int. 2016;97:117-24.

86. Lin $\mathrm{H}-\mathrm{l}$, Chen J-P, Wong GTF, Huang C-W, Lien C-C. Aerosol input to the South China Sea: results from the MODerate resolution imaging Spectroradiometer, the quick Scatterometer, and the measurements of pollution in the troposphere sensor. Deep Sea Res Pt II. 2007;54:1589-601. https://doi. org/10.1016/j.dsr2.2007.05.013.

87. Oh HR, Ho CH, Kim J, Chen D, Lee S, Choi YS, Chang LS, Song CK. Longrange transport of air pollutants originating in China: a possible major cause of multi-day highPM10 episodes during cold season in Seoul, Korea. Atmos Environ. 2015;109:23-30.

88. Zhu J, Liao H, Mao $Y$, Yang $Y$, Jiang $H$. Interannual variation, decadal trend, and future change in ozone outflow from East Asia. Atmos Chem Phys. 2017;17:3729-47. https://doi.org/10.5194/acp-17-3729-2017.

\section{Publisher's Note}

Springer Nature remains neutral with regard to jurisdictional claims in published maps and institutional affiliations.

\section{Ready to submit your research? Choose BMC and benefit from:}

- fast, convenient online submission

- thorough peer review by experienced researchers in your field

- rapid publication on acceptance

- support for research data, including large and complex data types

- gold Open Access which fosters wider collaboration and increased citations

- maximum visibility for your research: over $100 \mathrm{M}$ website views per year

At $\mathrm{BMC}$, research is always in progress.

Learn more biomedcentral.com/submissions 